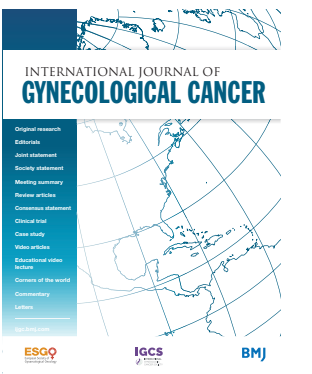

Department of Gynecology Oncology, La Fe University and Polytechnic Hospital, Valencia, Spain

Correspondence to Dr Pablo Padilla-Iserte, Department of Gynecology Oncolgy, La Fe University and Polytechnic Hospital, 46026 València, Spain; pablo_iserte@ hotmail.com

Accepted 23 April 2020 Published Online First 5 May 2020

\title{
Creatsas modified vaginoplasty as reconstructive treatment of vaginal stenosis due to vaginal or pelvic radiotherapy
}

Sheila Vazquez, Pablo Padilla-Iserte, Tiermes Marina, Victor Lago, Luis Matute, Santiago Domingo

Female sexuality is a complex phenomenon with important repercussions on patients' quality of life. Women survivors of gynecological malignancy might have sexual dysfunction after cancer treatment. Surgical radicality and radiation therapy might cause scar tissue in the vagina, being a common long term side effect. This fact generates a thickening and subsequent vaginal shortening, developing vaginal stenosis, which hinders sexual intercourse. The incidence appears highly variable $(2.5-88 \%)$ depending on patient age, surgical radicality, radiation doses, and vaginal dilator use. In certain cases, the anatomical defect should be restored, so reconstructive surgery may be necessary. ${ }^{1}$

The role of reconstructive surgery in sexual function improvement has already been evaluated in previous studies with promising results. ${ }^{2}$ Similar outcomes were obtained in patients with vaginal aplasia with the use of Creatsas modification of Williams vaginoplasty, with a great improvement in sex life after reconstruction. ${ }^{3}$ We present a patient with vaginal stenosis after chemoradiotherapy for locally advanced cervical cancer, in which we have used this procedure to restore the anatomical defect (Video 1). Under general anesthesia, a symmetrical $U$ shaped vulvar incision was made, starting $4 \mathrm{~cm}$ lateral to the external urethral meatus and medial to the labia majora. The perineal subcutaneous tissue was mobilized dorsally and the inner skin margins were sutured from below upwards in an interrupted fashion, keeping the knots towards the inside (2-0 absorbable suture) in order to create a vaginal pouch. The perineal muscles and subcutaneous fat were approximated with simple interrupted sutures. Finally, the lateral skin margins were sutured from below upwards in an interrupted fashion with fast absorbable suture.

Creatsas vaginoplasty is a safe surgical technique, which restores the anatomical defect and might help to improve the patient's sex life, in selected vaginal stenosis after oncologic treatment.

Twitter Tiermes Marina @Tiermes

Contributors All authors have actively participated in the elaboration of the manuscript.

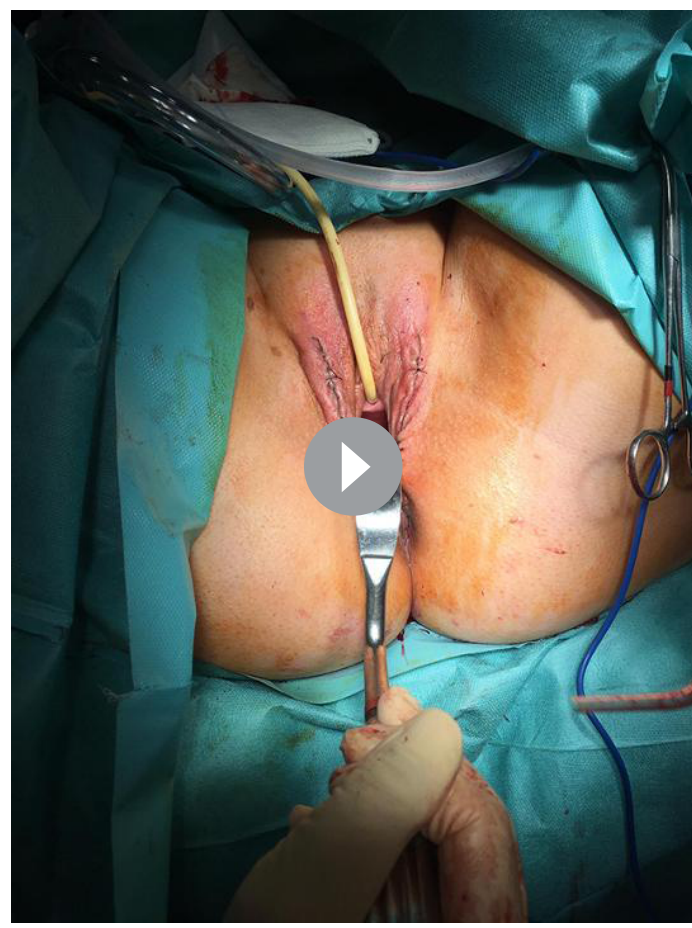

Video 1 Creatsas modified vaginoplasty.

Funding The authors have not declared a specific grant for this research from any funding agency in the public, commercial, or not-for-profit sectors.

Competing interests None declared.

Patient consent for publication Not required.

Provenance and peer review Not commissioned; externally peer reviewed.

Data availability statement Data are available in a public, open access repository

\section{REFERENCES}

1 Damast S, Jeffery DD, Son $\mathrm{CH}$, et al. Literature review of vaginal stenosis and dilator use in radiation oncology. Pract Radiat Oncol 2019;9:479-91.

2 Chen S-Q, Kong L-Z, Jiang H-Y, et al. Early cervica cancer impact of peritoneal vaginoplasty combined with laparoscopic radical hysterectomy improved sexual function. Int J Gynecol Cancer 2015;25:526-32.

3 Creatsas G, Deligeoroglou E. Creatsas modification of Williams vaginoplasty for reconstruction of the vaginal aplasia in Mayer-Rokitansky-Küster-Hauser syndrome cases. Womens Health 2010;6:367-75. 